\title{
Perpendicular Magnetic Printing Characteristics along Cross-track Direction on ECC Media
}

\author{
T. Kawamae, T. Komine, and R. Sugita \\ Ibaraki Univ., 4-12-1 Nakanarusawa-cho, Hitachi, Ibaraki 316-8511, Japan
}

\begin{abstract}
Magnetic printing characteristics along the cross-track direction on ECC media were investigated by using micromagnetic simulation. There is an optimum printing field in which the difference between ideal and calculated magnetization distributions is minimum except for checker patterns in edge printing. It was clarified that the difference in bit printing was smaller than that in edge printing. When the bit size becomes smaller, the ratio of the difference to the track pitch became larger. The difference in dot patterns was smaller than that in checker patterns for bit printing, whereas the difference in checker patterns was smaller than that in dot patterns for edge printing.
\end{abstract}

Key words: magnetic printing, bit printing, edge printing, ECC media, perpendicular magnetic recording, master pattern size

\section{ECC 媒体におけるクロストラック方向の磁気転写特性}

川前武士・小峰啓史・杉田龍二

茨城大学工学部, 茨城県日立市中成沢町 4-12-1（干316-8511）

\section{1. はじめに}

磁気転写法は, ハードディスクにサーボ信号を高速かつ 安価に書き込む方法として期待されている1) 3). 垂直記録 媒体（スレーブ媒体）に対する磁気転写法には，スレーブ 媒体に対し垂直に外部磁場を印加して転写するビット転写 (Bit Printing, BP) と, 水平に外部磁場を印加して転写す るエッジ転写 (Edge Printing, EP) がある4),5). サーボ信 号書き込み時にクロストラック方向における磁化状態の乱 れが存在すると, 再生時にエラーの原因になると考えられ る.しかし, クロストラック方向に着目した磁気転写特性 の検討は十分でない. 本研究では, マイクロマグネティッ クシミュレーションを用いて, ECC媒体におけるBP及び $\mathrm{EP}$ のロストラック方向の磁気転写特性を解析した.

\section{2. シミュレーション方法}

BP では，マスター磁性膜として垂直磁気異方性を有す る $\mathrm{CoPt}$ を想定した ${ }^{6)}$. 飽和磁化 $M_{\mathrm{s}}$ を $1300 \mathrm{emu} / \mathrm{cm}^{3}$ とし, 異方性磁場 $H_{\mathrm{k}}$ を $15 \mathrm{kOe}$, 正規分布を用いて与えた異方性 磁場分散 $\sigma_{H_{\mathrm{k}}}$ を $H_{\mathrm{k}}$ の $10 \%$ とした. BP では, 初めに, スレ 一ブ媒体垂直方向に初期磁場を印加し, 記録層を DC 消磁 する. 次にマスター磁性膜をスレーブ媒体に接触させ, 初 期磁場と逆向きに転写磁場 $H_{\mathrm{a}}$ を印加する. 転写磁場 $H_{\mathrm{a}}$ に よって, マスター磁性膜部に接触している記録層磁化が反 転し，サーボ信号が記録される。

$\mathrm{EP}$ では，マスター磁性膜として FeCo を想定した ${ }^{6)}$. $M$ s を $1900 \mathrm{emu} / \mathrm{cm}^{3}$ とし， $H_{\mathrm{k}}=0$ Oe とした， EPでは，BP と同様にスレーブ媒体を初期磁化し, マスター磁性膜をス レーブ媒体に接触させる. その後, ダウントラック方向に 転写磁場 $H_{\mathrm{a}}$ を印加する. 転写磁場 $H_{\mathrm{a}}$ を印加すると, マス ター磁性膜のエッジ部に磁場の垂直成分が発生する。記録 磁場の垂直成分により, 記録層磁化が反転し, サーボ信号
が記録される.

計算領域を 1 辺 $5 \mathrm{~nm}$ の立方体で離散化し, LandauLifshitz-Gilbert方程式を用いてマスター媒体磁性膜磁化 及び記録層に生じる記録磁場を計算した。求めた記録磁場 を用いて記録層の磁化状態を計算した。 シミュレーション モデルをFig. 1 に示す. 転写磁場印加時における立ち上が り時間を0 secとして計算した. サーボパターンとしてDot パターン及びCheckerパターンを想定した。 各々のマスタ 一磁性膜の形状をFig. 1(a)及び(b)に示す。マスター磁性膜 及びスレーブ媒体の側面図をFig. 1(c)に示す. マスター磁 性層及び記録層間の磁気スペーシングを $5 \mathrm{~nm}$ とし，記録 層は硬磁性層と軟磁性層で構成された $\mathrm{ECC}$ 媒体 ${ }^{7)}$ を想定し た。 ECC媒体は粒径5 $\mathrm{nm}$ の磁性粒子で構成されていると した．硬磁性層，及び軟磁性層の異方性磁場 $H_{\mathrm{k}}$ を $15 \mathrm{kOe}$ および5 $\mathrm{kOe}$ とた。いずれの層においても， $M_{\mathrm{s}}$ を 400 $\mathrm{emu} / \mathrm{cm}^{3}, \quad \sigma_{H_{\mathrm{k}}}$ を $H_{\mathrm{k}}$ の $10 \%$, 配向角度分散 $\Delta \theta_{50}$ を $10 \mathrm{deg}$. とした。硬磁性層の粒子内交換結合定数を $1.0 \times 10^{-6} \mathrm{erg} / \mathrm{cm}$, 両磁性層の粒子間交換結合定数を $1.0 \times 10^{-7} \mathrm{erg} / \mathrm{cm}$, 層間交 換結合定数を $3.0 \times 10^{-7} \mathrm{erg} / \mathrm{cm}$ とした ${ }^{7)}$. 以前の研究7),8)によ りマスター磁性膜のサイズを所望のビットサイズよりも小 さくすると転写特性が向上するため, 本研究でもマスター 磁性膜サイズを所望のビットサイズよりも小さく設定し た.

初めに, 理想的に転写されたサーボ信号のビットサイズ としてビット長 $B L=35 \mathrm{~nm}, \quad$ トラックピッチ $T_{\mathrm{p}}=50 \mathrm{~nm}$ を想定し, マスター媒体の磁性膜サイズを $L \mathrm{~nm} \times W \mathrm{~nm}$ と して, 転写特性の転写磁場依存性を調べた.

次に，ビットサイズを $25 \mathrm{~nm} \times 35 \mathrm{~nm}$ 及び50 nm×70 nm と変えて，転写特性のビットサイズ依存性を調べた。ビッ トサイズに対する BP及びEPのマスター磁性膜サイズを Table 1 に示す. 


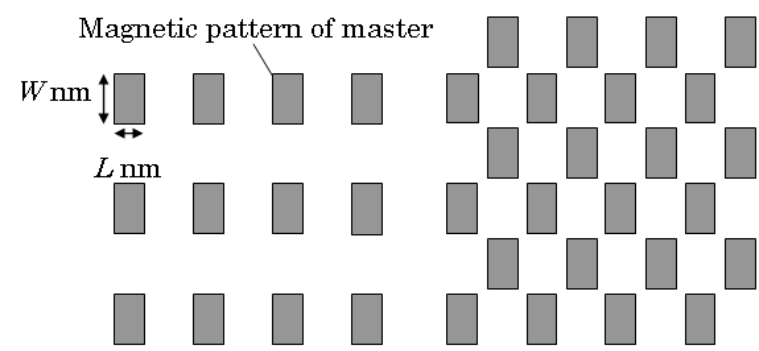

$\uparrow$ :Cross-track direction

$\stackrel{x}{\longrightarrow}$ :Down-track direction

(a) Dot pattern

(b) Checker pattern

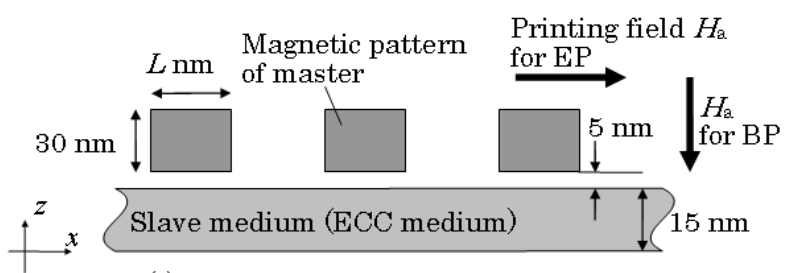

(c) Side view of master and slave media.

Fig. 1 Simulation model.

Table 1 Bit size and master pattern size of patterned magnetic film

\begin{tabular}{|c|c|c|}
\hline \multirow{2}{*}{$\begin{array}{l}\text { Bit size, } \\
B L \times T_{\mathrm{p}}\left[\mathrm{nm}^{2}\right]\end{array}$} & \multicolumn{2}{|c|}{ Master pattern size, $L \times W\left[\mathrm{~nm}^{2}\right]$} \\
\hline & $\mathrm{BP}$ & EP \\
\hline $25 \times 35$ & $15 \times 25$ & $25 \times 15$ \\
\hline $35 \times 50$ & $25 \times 40$ & $35 \times 20$ \\
\hline $50 \times 70$ & $40 \times 60$ & $50 \times 40$ \\
\hline
\end{tabular}

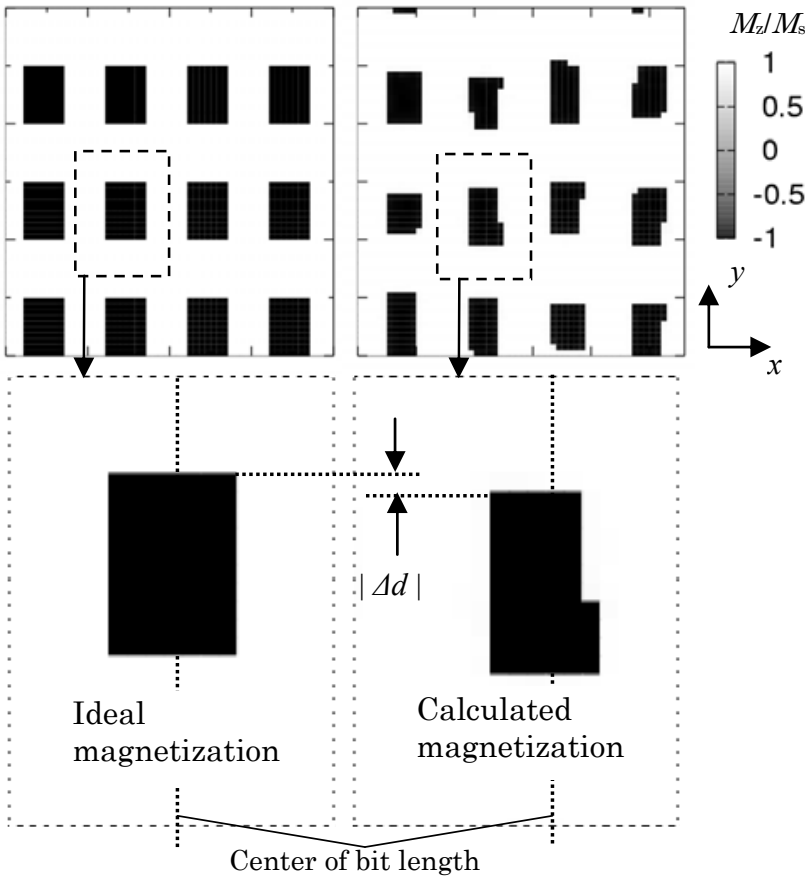

Fig. 2 Difference between ideal and calculated magnetizations, $|\Delta d|$, on center of bit length.

記録層に転写された磁化反転領域を評価するために，ク ロストラック方向 ( $y$ 方向) における理想的な磁化状態との 差 $|\Delta d|$ をFig. 2 のように定義した. $|\Delta d|$ の算出には, 記 録層表面の磁化を用いた. Fig. 2 の白い部分は磁化が+ $z$ 方
向を向いていることを表し，黒い部分は磁化がー $z$ 方向を 向いていることを表している.ビット長の中心線上におけ る磁化反転領域の端と理想的磁化状態の磁化反転領域の端 の差を各ビットにわたって平均した值を $|\Delta d|$ とした. ECC媒体における磁気特性の分散を考慮し，各箇所で生 じる理想状態との差を96箇所 (Fig. 2 のDotパターンには ドットが 12 個あり，磁気特性の分散を吸収するため，4回 計算を行い，1個のドットにつき上部と下部の 2 箇所の值を 求めたので, $12 \times 2 \times 4=96$ 箇所) で調べ平均した值を $|\Delta d|$ と した。 また，本研究では $|\Delta d|$ が最小となる転写磁場を最 適転写磁場 $H_{\mathrm{a}}^{\mathrm{opt}}$ とした.

\section{3. シミュレーション結果}

\section{1 転写磁場依存性}

転写磁場 $H_{\mathrm{a}}$ を変化させてスレーブ媒体に Dot パターン をビット転写した記録層表面の磁化状態を Fig. 3 に示寸. ビットサイズは $35 \mathrm{~nm} \times 50 \mathrm{~nm}$ とし，マスター磁性膜サイ ズを $25 \mathrm{~nm} \times 40 \mathrm{~nm}$ とした. 図の横方向がダウントラック 方向，縦方向がクロストラック方向である. 記録層の初期 磁化は $M_{\mathrm{z}} / M_{\mathrm{s}}=+1$ とし， $H_{\mathrm{a}}$ を一 $z$ 方向に印加した. Fig. 3 より $H_{\mathrm{a}}{ }^{\mathrm{opt}}=4 \mathrm{kOe}$ で理想的な磁化状態と同等の転写が得 られた。

Checker パターンをビット転写した記録層の磁化状態を Fig. 4 に示す. $|\Delta d|$ が最小となる転写磁場 $H_{\mathrm{a}}$ は $6 \mathrm{kOe}$ で あったが，いずれの磁化状態も，理想的な磁化状態に比べ, パターン形状が乱れていることがわかる.

ビット転写において $H_{\mathrm{a}}^{\mathrm{opt}}$ を印加したときの, Dot 及び Checker パターンのクロストラック方向における記録磁場 の垂直成分を Fig. 5 に示す.なお，記録磁場分布は，マス ター磁性膜の中心線上の值をプロットした．転写状態の違 いは Checker パターン及びDotパターン周囲の磁性膜が占 める面積に関係している. Checker パターンは, Dot パター

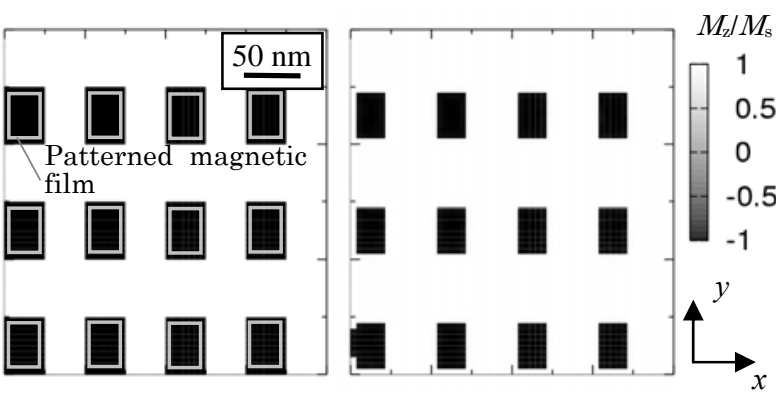

(a) Ideal magnetization

(b) $H_{\mathrm{a}}=3 \mathrm{kOe}$

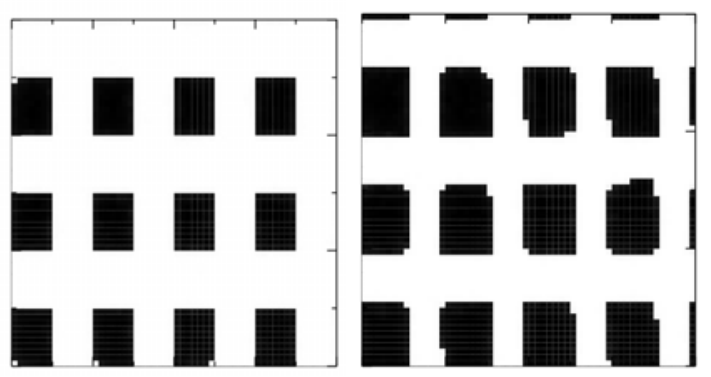

$\begin{array}{ll}\text { (c) } H_{\mathrm{a}}=4 \mathrm{kOe} & \text { (d) } H_{\mathrm{a}}=5 \mathrm{kOe}\end{array}$

Fig. 3 Magnetization distributions for printed recording layer with various printing fields $H_{\mathrm{a}}$ for $\mathrm{BP}$. 


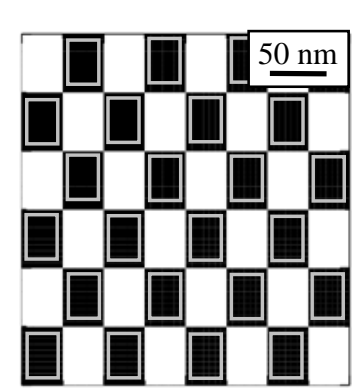

(a) Ideal magnetization

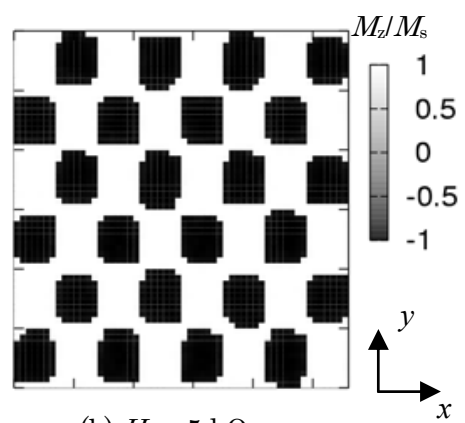

(b) $H_{\mathrm{a}}=5 \mathrm{kOe}$

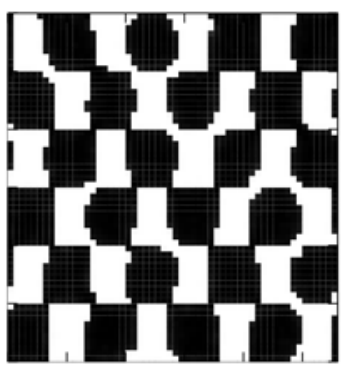

(c) $H_{\mathrm{a}}=6 \mathrm{kOe}$

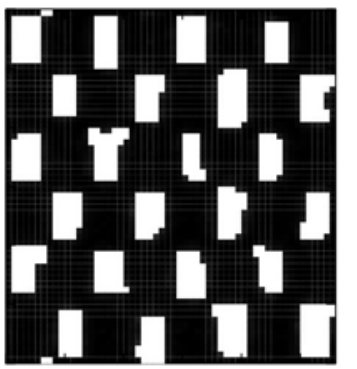

(d) $H_{\mathrm{a}}=7 \mathrm{kOe}$

Fig. 4 Magnetization distributions for printed recording layer with various printing fields $H_{\mathrm{a}}$ for BP.

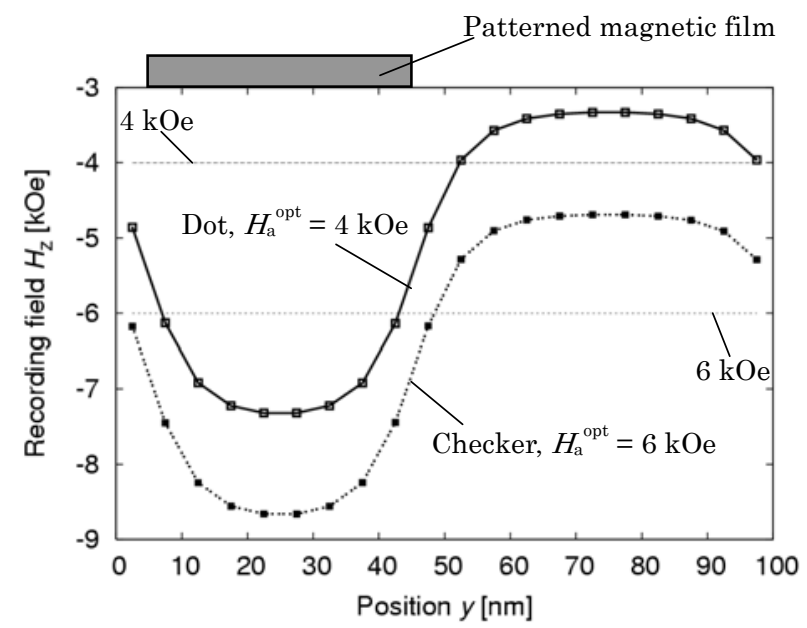

Fig. 5 Perpendicular component of recording field at center of bit length with BP.

ンに比ベてパターンが密集しているため, Fig. 5 に示すよ うに, 磁性膜に吸い込まれる磁束が減少し，転写磁場の垂 直成分が減少する。 その結果, 転写されたパターンの形状 が乱れたと考えられる。

次に, 転写磁場 $H_{\mathrm{a}}$ を変化させてスレーブ媒体にエッジ 転写を行った。 マスター磁性膜サイズを $35 \mathrm{~nm} \times 20 \mathrm{~nm}$ と した. 転写磁場 $H_{\mathrm{a}}$ をダウントラック $(x$ 方向 $)$ に印加した. Dot パターンをエッジ転写した記録層表面の磁化状態を Fig. 6 に示す. Fig. 6 より $H_{\mathrm{a}}^{\mathrm{opt}}=5 \mathrm{kOe}$ であったが, 理想 的な磁化状態と比較すると, クロストラック方向において 磁化転移ラインにばらつきがあることがわかる. Checker パターンをエッジ転写した記録層表面の磁化状態を Fig. 7 に示す. Fig. 7 より, CheckerパターンはDotパターンより クロストラック方向の磁化転移ラインの乱れが少ないこと がわかる。

エッジ転写において $H_{\mathrm{a}}^{\mathrm{opt}}$ を印加したときの, Dot 及び

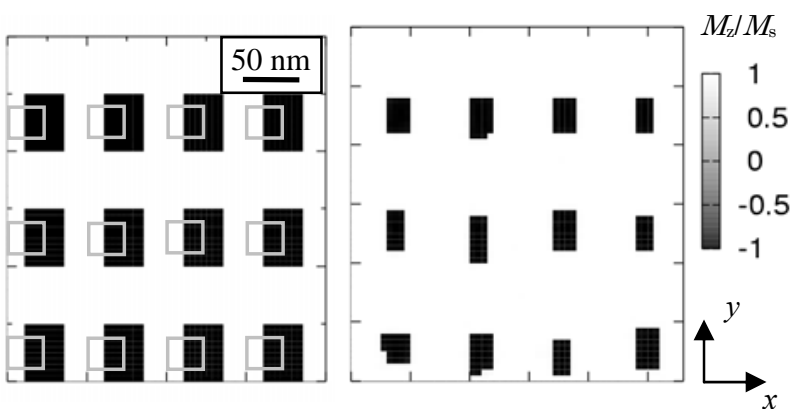

(a) Ideal magnetization

(b) $H_{\mathrm{a}}{ }^{\mathrm{opt}}=4 \mathrm{kOe}$

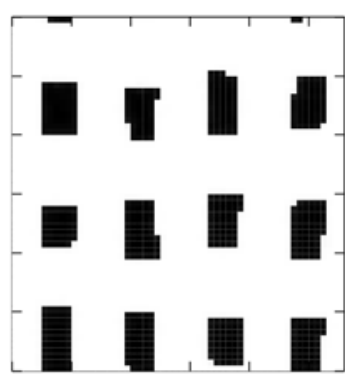

(c) $H_{\mathrm{a}}^{\mathrm{opt}}=5 \mathrm{kOe}$

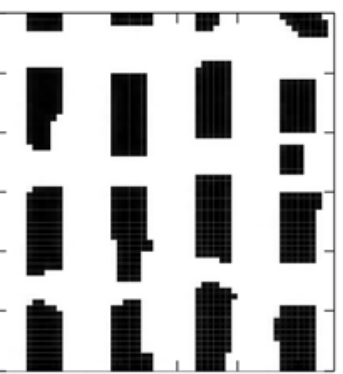

(d) $H_{\mathrm{a}}^{\text {opt }}=6 \mathrm{kOe}$

Fig. 6 Magnetization distributions for printed recording layer with various printing fields $H_{\mathrm{a}}$ for EP

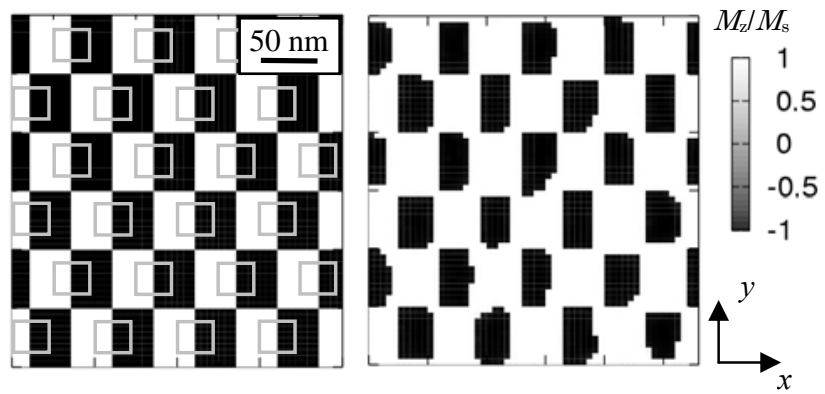

(a) Ideal magnetization

(b) $H_{\mathrm{a}}^{\text {opt }}=6 \mathrm{kOe}$,
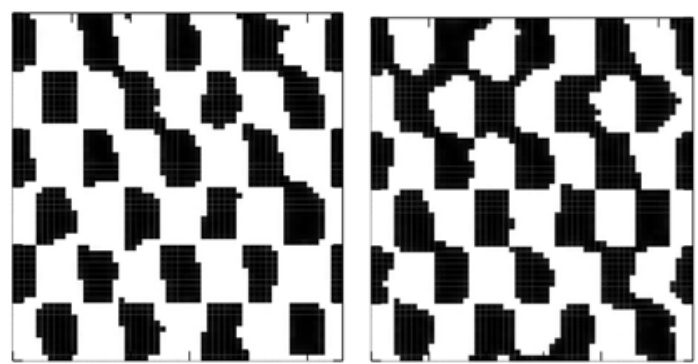

(c) $H_{\mathrm{a}}{ }^{\mathrm{pt}}=7 \mathrm{kOe}$

(d) $H_{\mathrm{a}}^{\text {opt }}=8 \mathrm{kOe}$

Fig. 7 Magnetization distributions for printed recording layer with various printing fields $H_{\mathrm{a}}$ for EP.

Checker パターンのクロストラック方向における記録磁場 の垂直成分を Fig. 8 に示す.なお，記録磁場分布は，記録 層表面の理想的な磁化反転領域の中心線上の值をプロット した. Fig. 8 より, Dotパターンでは, マスター磁性膜接触 部でのみ記録磁場が負である。一方, Checker パターンで は，マスター磁性膜がある部分では記録磁場が負であり， 無い部分では正である.また, Dotパターンにおける記録磁 場は Checker パターンよりも低く，端部の磁場勾配が緩や かである. 以上の理由から, Dotパターンにおいてクロスト ラック方向の磁化転移ラインが乱れたと推察される. 


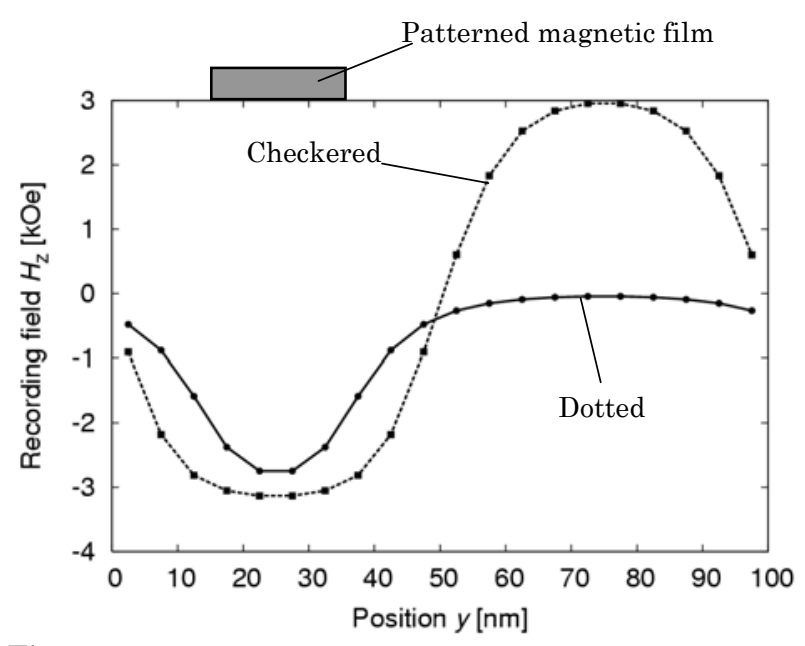

Fig. 8 Perpendicular component of recording field at center of bit length with EP.

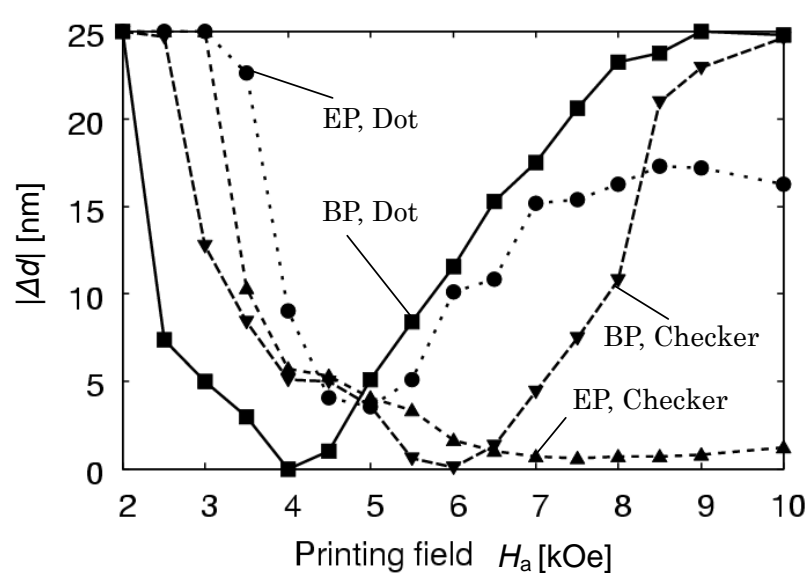

Fig. 9 Dependence of $|\Delta d|$ on printing field for various printing methods and patterns.

転写方法及び各パターンに対する $|\Delta d|$ の転写磁場依存 性を Fig. 9 に示す. Fig. 9 より, ビット転写では| $\Delta d \mid$ が最 小となる最適転写磁場が各パターンで異なっている. また, エッジ転写のChecker パターンでは最適転写磁場が存在せ ず, 転写磁場 $H_{\mathrm{a}}$ が高いほど優れた転写特性が得られるこ とがわかる. Checker パターンでは, 記録磁場の垂直成分 により，記録層の磁化が飽和したため，| $\Delta d \mid$ も飽和したと 考えられる.

\section{2 ビットサイズ依存性}

ビットサイズ変化させてスレーブ媒体に転写した場合の $|\Delta d|$ の割合を Fig. 10 に示す. 横軸はビットサイズの逆数 を表し, 縦軸はトラックピッチ $T_{\mathrm{p}}$ に対するクロストラック 方向の上下の偏差を合わせた $2|\Delta d|$ の割合を示した．転写 磁場はそれぞれの最適転写磁場 $H_{\mathrm{a}}^{\mathrm{opt}}$ を印加した. Fig. 10 よりビットサイズが小さくなると| $\Delta d \mid$ の割合が大きくな ることがわかる．これは，ビットサイズが小さくなると， 転写磁場のクロストラック方向の磁場勾配が緩やかになっ たためである. Fig. 10 より, ビット転写では, Dotパター ンより Checker パターンの方が| $\Delta d \mid$ が大きいが，エッジ 転写では Checker パターンより Dot パターンの方が $|\Delta d|$ が大きいことがわかる. Fig. 10 より，いずれのパターンに

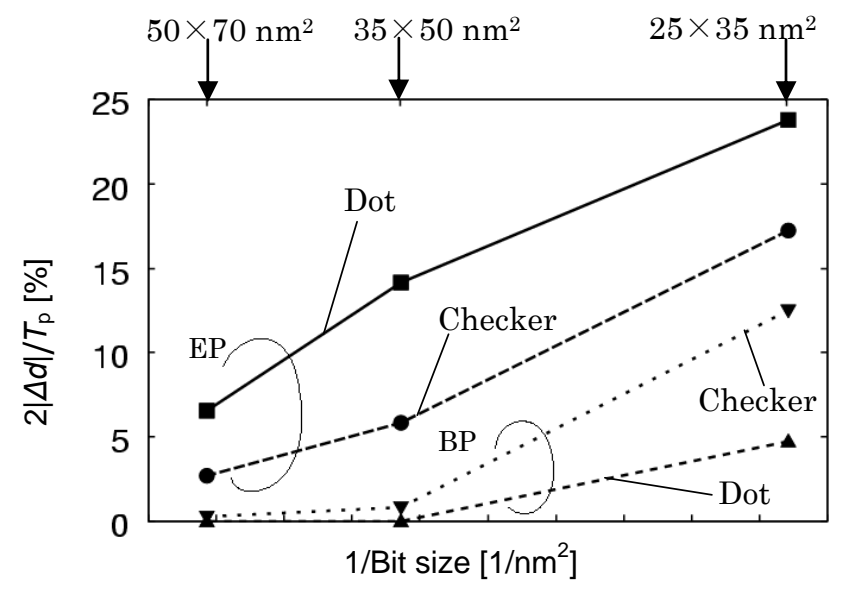

Fig. 10 Dependence of ratio, $2|\Delta d| / T_{\mathrm{p}}$, on bit size for various printing methods and patterns.

おいてもビット転写の方が| $\Delta d \mid$ が小さく, エッジ転写の方 が磁化転移ラインの乱れが大きいことがわかった。

\section{4. まとめ}

本研究では，マイクロマグネティックシミュレーション を用いて，ECC 媒体に転写された信号のクロストラック方 向における磁気転写特性について検討した. エッジ転写の Checker パターン以外では理想的な磁化状態との差 $(|\Delta d|)$ が最小となる転写磁場が存在し, エッジ転写よりビット転 写のほうが $|\Delta d|$ が小さいことがわかった.また，ビットサ イズを小さくすると，トラックピッチに対する $|\Delta d|$ の割合 が大きくなることがわかった.ビット転写では Dot パター ンの方が $|\Delta d|$ が小さく, エッジ転写では Checker パター ンの方が $|\Delta d|$ が小さいことがわかった．また，ビット転写 はエッジ転写に比べてより高密度でも十分なサーボ信号品 質を有すると推察される.

謝辞 本研究の一部は, 日本学術振興会科学研究費補助金 基盤研究 $\mathrm{B}(21360159)$ の支援により行われました。また富 士フイルム (株)の皆様にご協力，ご議論を頂きました。こ こに深謝致します.

\section{References}

1) T. Komine, T. Murata, and R. Sugita: IEEE Trans. Magn., 44, 3416 (2008).

2) Y. Sakaguchi, T. Murata, T. Komine, and R. Sugita: J. Magn. Soc. Jpn., 32, 221 (2008).

3) T. Murata, Y. Sakaguchi, A. Izumi, T. Komine, and R. Sugita: J. Magn. Soc. Jpn., 32, 230 (2008).

4) K. Tanabe, T. Saito, N. Sheeda, T. Komine, and R. Sugita:J. Magn. Soc. Jpn., 34, 173 (2010).

5) M.Onose, R. Kawasaki. Y. Tanaka, Y. Kawada, T. Komine, and R. Sugita: J. Magn. Soc. Jpn., 35, 356 (2011).

6) M. Nakazawa, H. Konishi, N. Sheeda, T. Komine, and R. Sugita: J. Magn. Soc. Jpn., 33, 64 (2009).

7) T. Murakoshi, T. Komine, and R. Sugita: J. Magn. Soc. Jpn. 34, 200 (2010).

8) T. Kawamae, T. Komine, and R. Sugita: J. Magn. Soc. Jpn., 35,335 (2011) 